\title{
Experimental and numerical investigation of backward erosion piping in heterogeneous sands
}

\author{
G. Negrinelli \\ University of Brescia, Brescia, Italy/Deltares, Delft, The Netherlands \\ V.M. van Beek \\ Deltares, Delft, The Netherlands \\ R. Ranzi \\ University of Brescia, Brescia, Italy
}

ABSTRACT: Backward erosion piping is a relevant failure mechanism for water-retaining structures that determines uncertainty in residual flooding hazard and risk mapping. The occurrence of piping can be predicted using the Sellmeijer model, which is developed and validated for homogeneous granular layers. However, the subsurface encountered below levees can be far from homogeneous. Previous laboratory tests indicated a substantial increase of piping resistance in sand samples with variation of properties in the path of the pipe. In the research described in this paper the process of backward erosion piping in heterogeneous sands was investigated by means of small-scale experiments to study the influence of micro-scale and macro-scale heterogeneity. Numerical simulations of piping experiments with macro-scale heterogeneity were performed using a 2D groundwater flow model extended with a piping module and a $3 \mathrm{D}$ groundwater flow model.

\section{INTRODUCTION}

Backward erosion piping is an internal erosion mechanism that occurs in the granular foundation of water-retaining structures built on a cohesionless sandy aquifer covered by a cohesive top layer (Fig. 1 ). The presence of a hydraulic gradient across the structure results in a groundwater flow through the aquifer. It can remove and transport sand grains, thereby resulting in the formation of sand boils and forming shallow pipes at the interface between the granular layer and the cohesive overlying material. The pipes develop backwards from the toe up to the river side leading to severe erosion of the foundation and to the failure of the structure.

Backward erosion piping is a relevant failure mechanism for water-retaining structures. Subsoil conditions sensitive to piping are common for river levees. Several levee failure events have been attributed to piping (Vrijling 2010, Calabresi et al. 2013, Camici et al. 2015), determining uncertainty in residual flooding hazard and risk mapping (Aureli

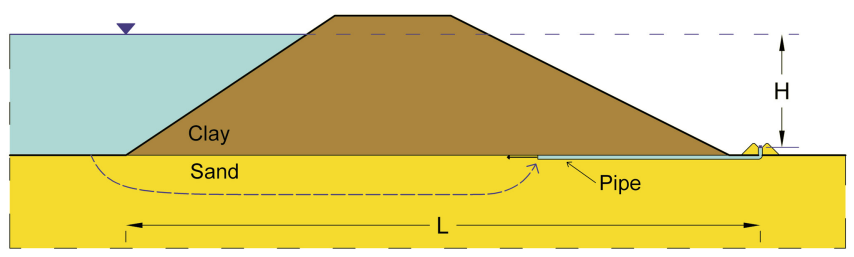

Figure 1. Schematised process of seepage and pipe development through a sandy aquifer under an impervious levee.
\& Mignosa 2004, Ranzi et al. 2013, Mazzoleni et al. 2014).

The occurrence of piping can be predicted, for instance, using the Sellmeijer model (Sellmeijer et al. 2011). The model describes the process of pipe progression simulating the groundwater flow through the granular aquifer, the laminar flow in the pipe and the limit equilibrium of grains at the bottom of the pipe. This model considers two-dimensional pipe and groundwater flow. It assumes that the main mechanism of pipe progression is secondary erosion, which is erosion of grains in the piping channel caused by the flowing of water through the pipe; it neglects primary erosion, which is erosion at the tip of the piping channel and which occurs, according to Van Beek et al. (2015), when the local gradient at the tip of the pipe exceeds a critical value resulting in fluidization and transporting of the grains. The Sellmeijer model can estimate the critical hydraulic head across the structure that causes the complete development of the pipe and leads to failure.

The Sellmeijer model is developed and validated only for homogeneous granular layers. However, the subsurface encountered below levees can be far from homogeneous. Variation in soil properties from micro-scale to macro-scale is common in the field due to complexity of the geology of the shallow subsurface of river systems.

Previous laboratory tests (Van Beek et al. 2008, Van Beek et al. 2015) have indicated a substantial increase of piping resistance in sand samples characterized by variation of properties in the path of the 


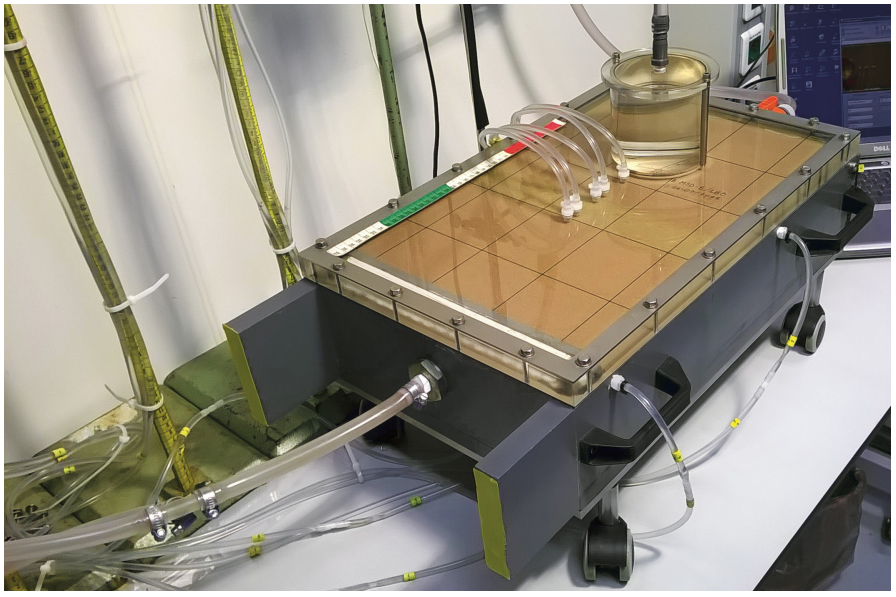

Figure 2. Small-scale experimental setup.

pipe like grain size and relative density. It has been noted that the Sellmeijer model fails to correctly predict the critical head when the pipe is formed through various types of sand and heterogeneities are present in horizontal direction.

In the research described in this paper the process of backward erosion piping in heterogeneous sands was investigated by means of small-scale experiments in order to study the effect of micro-scale and macro-scale heterogeneity on progression of pipe development. Subsequently, numerical simulations of piping experiments in case of macro-scale heterogeneity were performed. The possibility of prediction of the experimental results by means of MSeep, a 2D groundwater flow model extended with a piping module (Deltares, 2016), was tested. Then MODFLOW, a 3D groundwater flow model, was adopted in order to have insight in the influence of piping on the seepage pattern through the heterogeneous sandy aquifer.

\section{EXPERIMENTAL STUDY}

\subsection{Setup and method}

The process of backward erosion piping was investigated by means of small-scale experiments with circular outlet configuration, which have been described in detail in Van Beek et al. (2015). The experiments were performed using a setup consisting of a rigid box filled with sand covered by a transparent plate, a water supply system and several riser tubes to measure pore pressure at various locations in the sand sample (Figs 2,3). The sand sample simulated the sandy aquifer underneath a levee and its dimensions (length, width and height) were $0.484 \times 0.30 \times 0.101 \mathrm{~m}$. A horizontal hydraulic gradient was applied to the box during the experiment. Water entered into the container through a permeable filter, which corresponded to the river side of the levee. A circular hole in the transparent cover allowed the exit of the flow. This type of outlet simulated the case in which at the land side of the levee

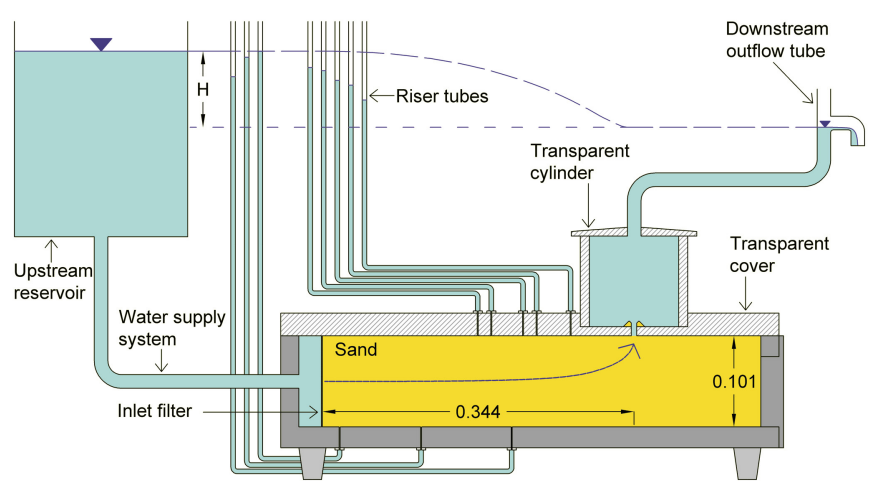

Figure 3. Schematic cross-section of the small-scale experimental setup (all dimensions are in meters).

Table 1. Sand characteristics in experiments

\begin{tabular}{lllll}
\hline Sand type & $\begin{array}{l}\mathrm{d}_{70}: \\
\mathrm{mm}\end{array}$ & $\mathrm{d}_{60} / \mathrm{d}_{10}$ & $\begin{array}{l}\text { Min. wet } \\
\text { porosity }\end{array}$ & $\begin{array}{l}\text { Max. wet } \\
\text { porosity }\end{array}$ \\
\hline Enschedé sand & 0.431 & 1.6 & 0.320 & 0.411 \\
Itterbeck mixture 2 & 0.203 & 3.2 & 0.319 & 0.440 \\
Baskarp & 0.140 & 1.5 & 0.367 & 0.475 \\
Itterbeck 431 $\mu \mathrm{m}$ & 0.505 & 2.6 & 0.285 & 0.380 \\
Itterbeck 333 $\mu \mathrm{m}$ & 0.349 & 2.1 & 0.307 & 0.409 \\
\hline
\end{tabular}

the sandy aquifer was covered by a confining cohesive layer locally broken by an open exit. Because of this configuration, the seepage flow concentrated near the exit reaching high flow velocities and forming a sand boil. The center of the hole had a diameter of $6 \mathrm{~mm}$ and it was located at a distance, corresponding to the seepage length of the model, of 34.4 $\mathrm{cm}$ from the upstream side of the setup. This configuration guaranteed the pipe initiation at a low hydraulic head drop and allowed the investigation of pipe progression.

In all the experiments the sand sample was prepared using the wet method described by Van Beek et al. (2015) which consisted in raining dry sand into the box, which was in upright position and filled with de-aired water, and continuously tamping it for compaction. In this way it was possible to prepare a fully saturated and dense (bulk relative density RD > $85 \%$ ) sand sample. Various sand types were tested. An overview of the characteristics of these sands is presented in Table 1.

The experiments were performed raising stepwise the hydraulic head over the sand sample of 0.5 or 1 $\mathrm{cm}$ every 5 or 10 minutes until the process of piping was observed through the transparent cover. When erosion took place, the hydraulic head drop was maintained constant until the erosion process stabilized. The experiments were stopped when the pipe reached the upstream filter, indicating that the critical head was reached. During the experiments the riser tubes installed in the bottom and in the lateral sides of the box measured the pore pressure of the sand sample, the riser tubes installed in the cover plate measured the hydraulic head near and in the pipes, flow rate through the sand sample was monitored and occasionally coloured fluid was injected in 


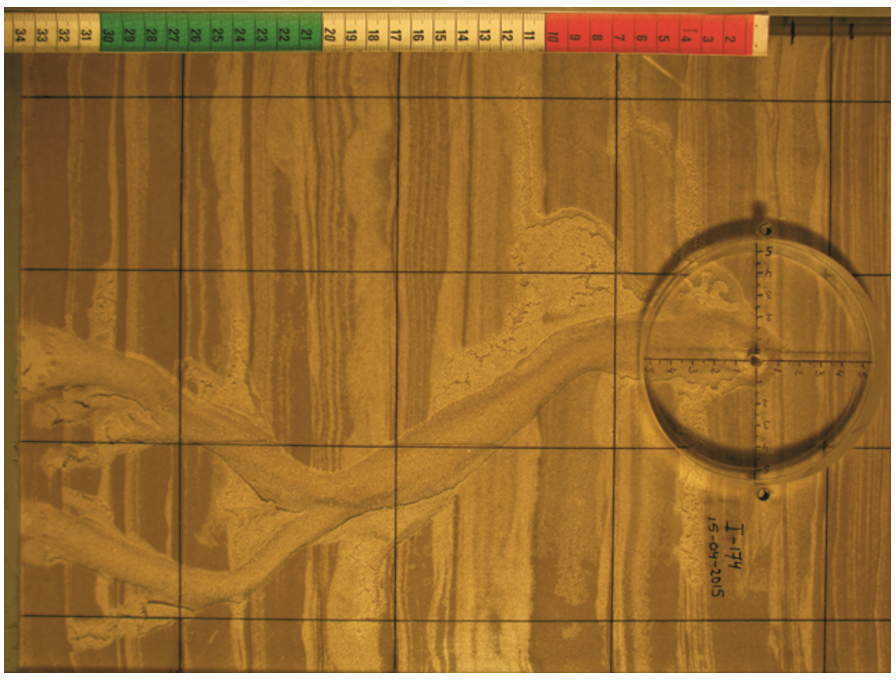

Figure 4. Sand sample of test I-174 during drainage.

Table 2. Overview of micro-scale heterogeneity experiments

\begin{tabular}{lllll}
\hline Exp. no. & Sand type & $\begin{array}{l}\mathrm{K}: \\
\mathrm{m} / \mathrm{s}\end{array}$ & $\mathrm{RD}$ & $\begin{array}{l}\text { Critical } \\
\text { head: } \mathrm{m}\end{array}$ \\
\hline E-173 & Enschedé sand & $4.83 \mathrm{E}-04$ & 0.90 & 0.115 \\
I-174 & Itterbeck mixture 2 & $2.49 \mathrm{E}-05$ & 0.85 & 0.280 \\
I-175 & Itterbeck mixture 2 & $2.15 \mathrm{E}-05$ & 0.87 & 0.410 \\
\hline
\end{tabular}

the water supply system of the experimental setup to visualize the flow pattern.

\subsection{Micro-scale heterogeneity experiments}

In the first series of experiments the effect of microscale heterogeneity on piping was investigated. Micro-scale variations are naturally present in the field, resulting in local differences of sand properties in the path of the pipe. They were reproduced by preparing a sand sample in which a sequence of layers, having small variations in sand properties, was created perpendicular to the flow direction. The preparation technique has been described in more detail in De Lange et al. (2016). The sample was prepared using the wet method and layering occurred because of segregation. When sand was rained into the box, the heavier and coarser grains settled quickly at the bottom whereas the lighter and finer grains floated at the top and fell slowly in the water. Accumulation of fine sand grains resulted in the formation of thin layers, causing local variation of properties like grain size and relative density. One test was performed using Enschedé sand, while two other tests were performed using Itterbeck mixture 2 sand, which is a finer and better graded non-uniform sand type.

Overview of the experiments is presented in Table 2. At the end of the experiments the sand sample was drained in order to visualize micro-scale heterogeneity. Drainage was performed from the bottom riser tubes and allowing the entrance of air at the top of the box. Pore water was gradually extracted from sand and zones of different water retention capacity

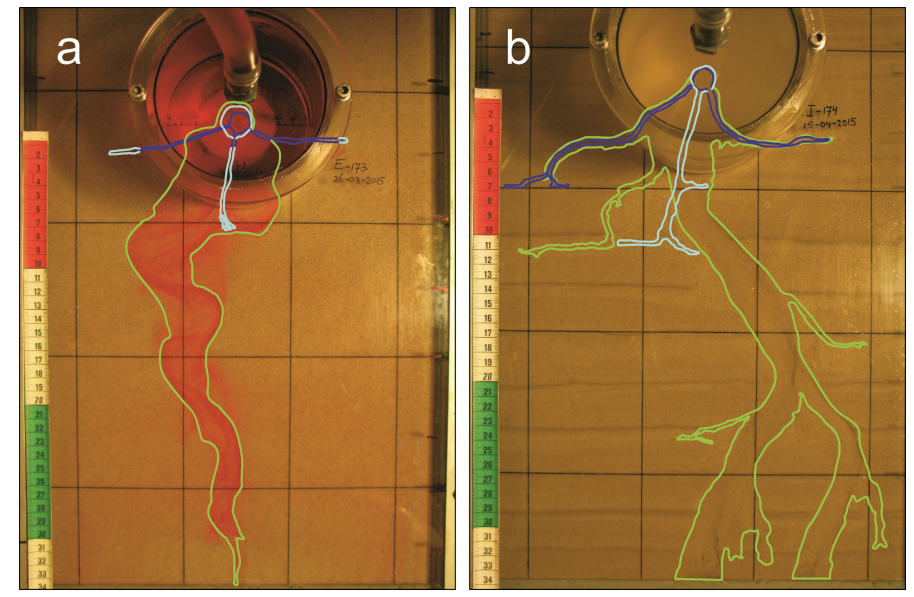

Figure 5. Area of the sample affected by piping at different stages of pipe development for test E-173 (a) and I-174 (b).

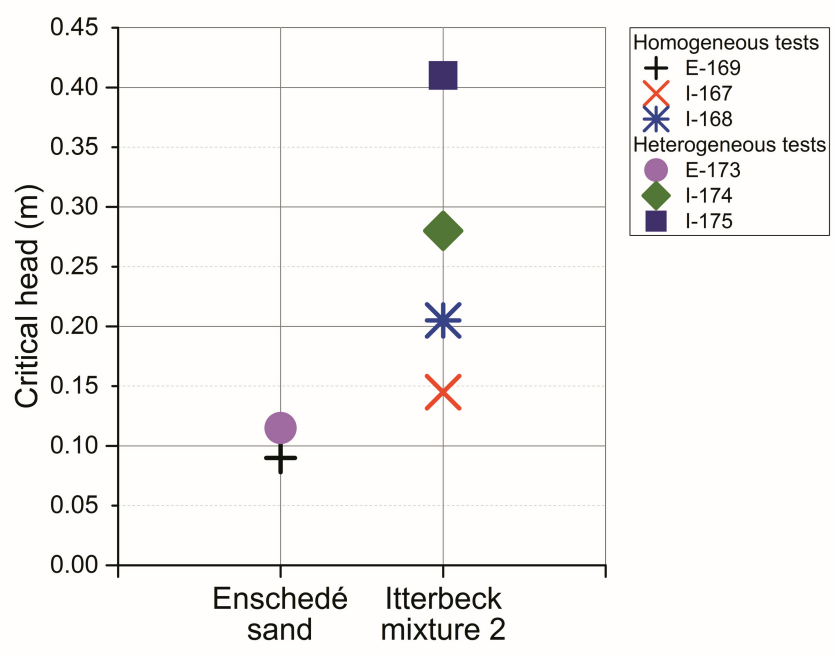

Figure 6. Critical head for micro-scale heterogeneity experiments.

were visible on the upper surface of the sample. Sand zones in which the voids had remained moist showed a dark colour, while the dry ones were light. Therefore, it was possible to highlight micro-scale variation in sand properties because water retention capacity depends on dimension of voids between particles and it is related to granulometric composition and density condition of sand. Figure 4 shows the sample of test I-174 during drainage. The alternation of thin layers of saturated sand became visible, in which the darker coloured areas correspond to a finer granulometric composition and larger relative density.

Photos of different stages of pipe development during the experiments are shown in Figure 5 for different sand types. Photos reveal that progression of pipe development was influenced by micro-scale heterogeneity. At the beginning of each experiment the pipe started to form perpendicular to the direction of the flow. It was observed that only after a significant increase of head the pipe passed through the first layer created by accumulation of fines and it continued to develop in upstream direction. For each considered sand type, tests with a layered sand sam- 
ple were compared to homogeneous equivalent experiments conducted by Van Beek et al. (2015) in order to evaluate the effect of micro-scale heterogeneity in the path of the pipe on piping resistance. The critical head for piping progression is plotted in Figure 6. It was found that experiments with a layered sand sample resulted in a critical head higher than the one of homogeneous equivalents. It was noted that layering and increase of strength was greater for non-uniform sand samples. It was found that in case of tests performed on Itterbeck mixture 2 sand, which is a non-uniform sand type, due to micro-scale heterogeneity the hydraulic conductivity of the layered sand samples was lower than the one measured by Van Beek et al. (2015) for homogeneous equivalent experiments.

The effect of micro-scale heterogeneity on the piping process could be explained considering that, in a layered sand sample, layers of fines with higher relative density led to local decrease of permeability and layers with relatively coarse grains, which were expected to be located exactly downstream each layer of fines due to the preparation method, were more difficult to erode, according to Van Beek et al. (2015).

\subsection{Macro-scale heterogeneity experiments}

In the second series of experiments the effect of macro-scale heterogeneity on piping was investigated. Macro-scale heterogeneity can be caused by the presence of coarse granular lenses in the levee subsurface or it may also correspond to the situation in which a coarse sand barrier is installed underneath a levee to interrupt the growth of the pipe (Koelewijn et al. 2014). Macro-scale heterogeneity was reproduced preparing a sample consisting of homogeneous fine sand with an intermediate zone of homogeneous coarse sand. The preparation technique has been described in more detail in De Lange et al. (2016). The sample was prepared using the wet method and ensuring homogeneity of each sand zone by continuous tamping and sand sprinkling. Fine Baskarp sand was used in all the tests. In three tests there was an intermediate zone of about $4 \mathrm{~cm}$ of medium coarse Itterbeck $431 \mu \mathrm{m}$ sand placed at a distance of $18.4 \mathrm{~cm}$ from the upstream side of the setup. Two other tests were performed using an intermediate zone of about $5 \mathrm{~cm}$ of medium coarse Itterbeck $333 \mu \mathrm{m}$ sand placed at a distance of 18.4 $\mathrm{cm}$ from the upstream side of the setup. As suggested by Koelewijn et al. (2014), filter criteria were adopted in order to verify for each test if the intermediate coarse sand layer had sufficient permeability, if it could retain the finer fraction of the sand sample and if it was internally stable. While for tests performed on Itterbeck $431 \mu \mathrm{m}$ and Itterbeck 333 $\mu \mathrm{m}$ sand the sample met the retention and internal stability criteria, the permeability criterion was not

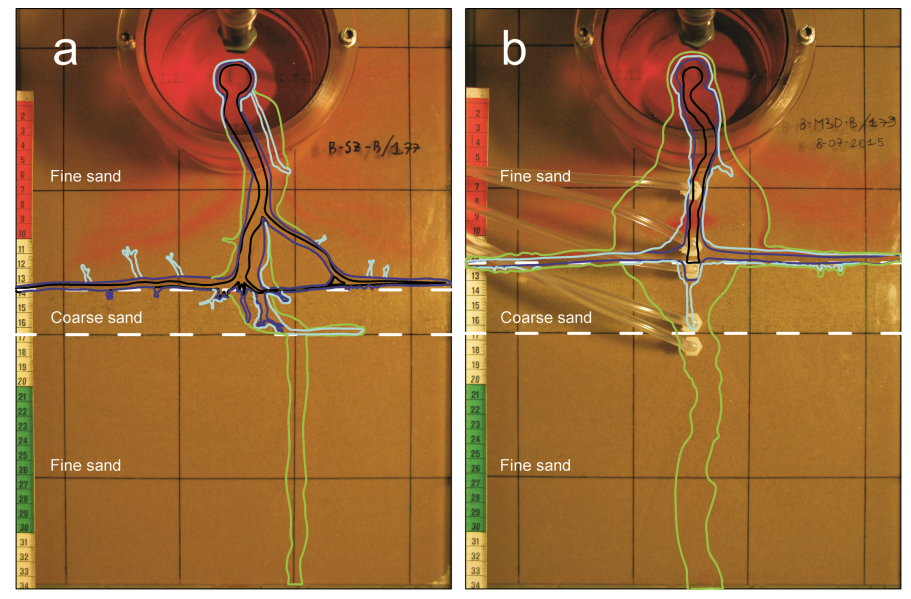

Figure 7. Area of the sample affected by piping at different stages of pipe development for test B-SZ-B-177 (a) and BM3D-B-179 (b)

Table 3. Overview of macro-scale heterogeneity experiments

\begin{tabular}{lllll}
\hline Exp. no. & $\begin{array}{l}\text { Coarse sand } \\
\text { type }\end{array}$ & $\begin{array}{l}\mathrm{K}_{\text {coarse }} \text { m/s } \\
\mathrm{m}\end{array}$ & $\begin{array}{l}\text { RD } \\
\text { Critical } \\
\text { head: } \mathrm{m}\end{array}$ \\
\hline B-SZ-B-176 & Itterbeck 431 $\mu \mathrm{m}$ & $1.03 \mathrm{E}-04$ & 0.90 & 0.275 \\
B-SZ-B-177 & Itterbeck 431 $\mu \mathrm{m}$ & $1.00 \mathrm{E}-04$ & 0.87 & 0.370 \\
B-SZ-B-178 & Itterbeck 431 $\mu \mathrm{m}$ & $1.03 \mathrm{E}-04$ & 0.95 & 0.400 \\
B-M3D-B-179 Itterbeck 333 $\mu \mathrm{m}$ & $1.19 \mathrm{E}-04$ & 0.95 & 0.320 \\
B-M3D-B-180 Itterbeck 333 $\mu \mathrm{m}$ & $1.19 \mathrm{E}-04$ & 0.95 & 0.490 \\
\hline
\end{tabular}

satisfied and for this reason, according to CUR (2010), progressive accumulation of fines was likely to be expected in the pores of the coarse sand layer at the upstream interface.

Overview of the experiments is presented in Table 3. In Figure 7 photos of the different stages of pipe development during the experiments are shown for different sand types. Photos reveal that in each experiment progression of pipe development was influenced by macro-scale heterogeneity, although significantly different erosion patterns were observed. In accordance with observations of Van Beek et al. (2008), in each experiment the pipe developed in the fine sand and it stopped at the downstream interface between fine and coarse sand. Increase of head resulted in deepening and widening of the erosion channel in the fine sand and the pipe developed perpendicular to the direction of the flow and adjacent to the downstream fine-coarse sand interface. After the increase of the head, the pipe passed through the interface. As it is possible to see from Figure 8, where the straight pipe length is plotted for each experiment as a function of the applied head, channel formation in the intermediate coarse sand layer occurred in different ways. In all the experiments equilibrium in pipe progression was observed in the intermediate coarse sand layer. In test B-SZ-B-178 pipe growth was interrupted in the middle of the intermediate sand layer. Lengthening of the pipe restarted only after a significant increase of head and it developed towards the upstream side of the setup without any further head increase. In the other experiments stepwise increase of head resulted 


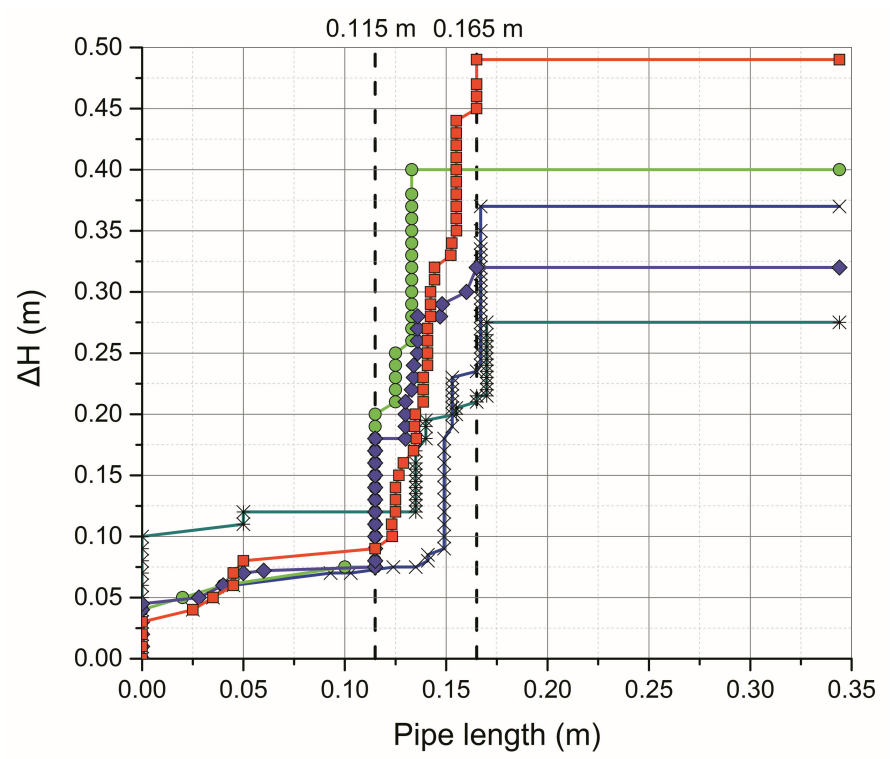

\begin{tabular}{|c|c|}
\hline $\begin{array}{l}\text { Test series B-SZ-B } \\
\text { - Fine sand: Baskarp B15 } \\
\text { - Coarse sand: Itterbeck } 431 \mu \mathrm{m}\end{array}$ & $\begin{array}{l}\text { Test series B-M3D-B } \\
\text { - Fine sand: Baskarp B15 } \\
\text { - Coarse sand: Itterbeck } 333 \mu \mathrm{m}\end{array}$ \\
\hline * B-SZ-B-176 & $\leadsto$ B-M3D-B-179 \\
\hline * B-SZ-B-177 & $\rightarrow B-M 3 D-B-180$ \\
\hline - - B-SZ-B-178 & \\
\hline
\end{tabular}

Figure 8. Pipe length as a function of the hydraulic head for macro-scale heterogeneity experiments.

in gradual pipe development through the coarse sand in upstream direction. In test B-M3D-B-179 the pipe passed through the middle of the downstream fine-coarse sand interface; from here only one erosion channel developed through the intermediate layer. In test B-M3D-B-180 failure of the downstream interface took place simultaneously in different points and several erosion channels developed slowly from the downstream interface through the intermediate layer up to the upstream interface. In tests B-SZ-B-176 and B-SZ-B-177 several erosion channels developed from the downstream interface, but only one central pipe reached the upstream interface. While in most of the conducted experiments the pipe quickly developed when it reached the upstream coarse-fine sand interface, in tests B-SZ-B176 and B-SZ-B-177 the pipe stopped at the upstream coarse-fine sand interface and the pipe passed through it only after a further head increase. It was observed that in test B-SZ-B-177 the pipe developed also parallel to the upstream interface.

In order to evaluate the effect of macro-scale variation in grain size in the path of the pipe on piping resistance, experiments with macro-scale heterogeneity were compared to tests conducted by Van Beek et al. (2015) in which equivalent homogeneous fine sand samples have been used. The critical head for piping progression of these experiments is plotted in Figure 9. It must be noted that results of test $\mathrm{B}-\mathrm{SZ}-\mathrm{B}-176$ were not considered reliable due to issues occurred during the preparation of the experiment. It was found that the critical head for piping progression through the downstream fine sand layer

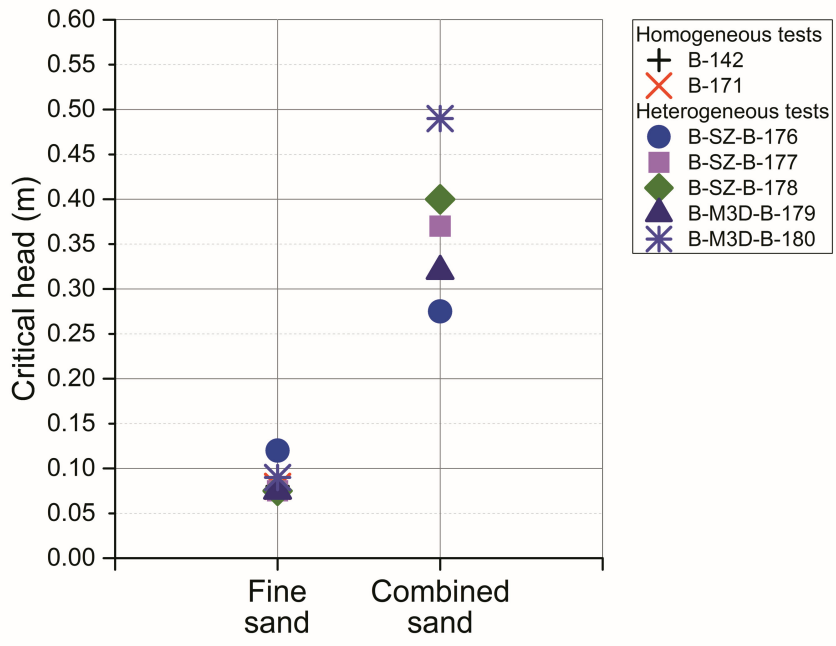

Figure 9. Critical head for macro-scale heterogeneity experiments.

was lower in case of heterogeneous tests. As observed also in experiments by Van Beek et al. (2008), this result was likely to be caused by the fact that since heterogeneous sand samples contained an intermediate layer of coarse sand, their permeability was higher compared to equivalent tests on homogeneous fine sand.

It was found that experiments with an intermediate coarse sand layer resulted in a final critical head for piping progression higher than the one of homogeneous fine sand equivalents, with an increase by a factor of 3-4. According to Van Beek et al. (2015), the presence of the intermediate coarse sand layer was expected to result in a large increase of strength of the sand sample because, when the layer with coarser grains was encountered by the pipe, a larger zone needed to be fluidized upstream the pipe tip. Therefore, lengthening was interrupted and pipe formation occurred in direction perpendicular to the layer interface through fine sand until the overall head was such that the local gradient in the coarse sand upstream the pipe was high enough to cause primary erosion. Interruption of pipe development near the upstream coarse-fine sand interface observed in some experiments was likely to be caused by the permeability contrast, which resulted in a decrease of the gradient upstream of the pipe when the piping channel progressed further into the coarse sand. It was found that while tests B-SZ-B-177 and B-SZ-B-178 had an acceptable reproducibility of the results, in case of tests B-M3D-B-179 and BM3D-B-180 the difference of critical head was very large, although their sand samples had the same characteristics and a correlation should have been expected between piping resistance of the sample and grain size of the intermediate coarse sand layer. This result could be explained by taking into account the influence on the groundwater flow through the sand sample of the different erosion patterns that were observed in the two experiments. Contrary to 


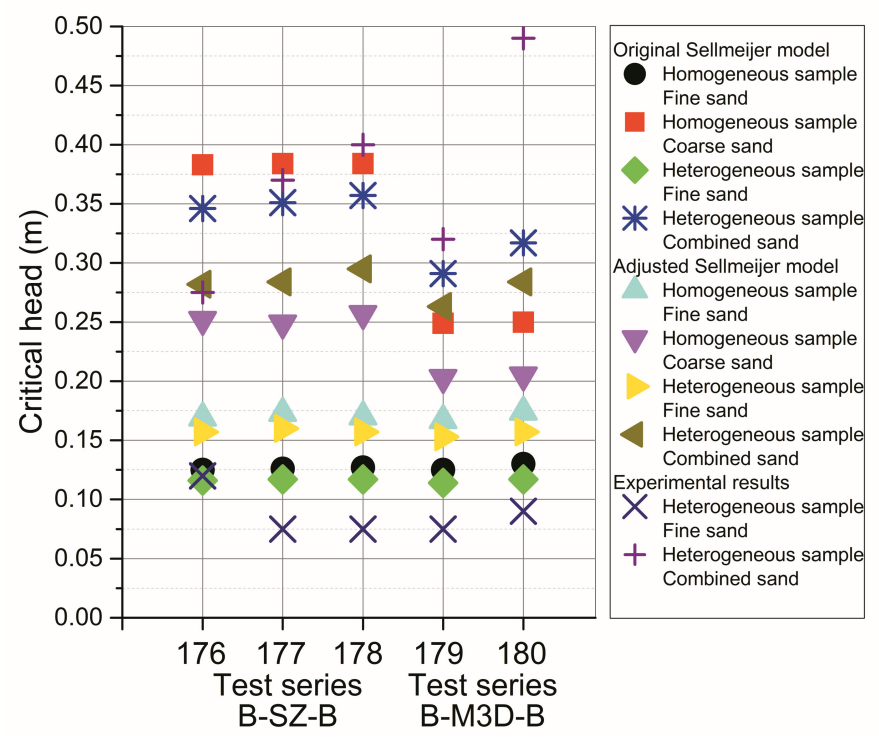

Figure 10. Overview of critical heads computed by MSeep.

the second experiment, in test B-M3D-B-179 only one pipe developed through the intermediate layer, which was expected to lead to a denser concentration of flow lines close to the pipe tip. This situation led, for the same overall head, to a higher local gradient at the tip of the pipe by comparison to test BM3D-B-180, in which the same flow was distributed among multiple erosion channels, and therefore pipe progression could occur at a lower overall gradient.

\section{NUMERICAL STUDY}

\section{$3.12 D$ numerical simulation}

The program MSeep analyses two-dimensional stationary groundwater flow using the finite element method to solve the differential equation of Laplace. In MSeep an internal erosion module based on the theory of Sellmeijer is implemented in order to simulate the backward erosion piping phenomenon (Sellmeijer 2006). The possibility to predict the results of the piping experiments with macro-scale heterogeneity using MSeep was investigated.

Setup of the numerical model was performed using the approach described by Van Beek et al. (2008). Water and sand properties were defined on the basis of experimental data and the twodimensional model geometry was defined in order to reproduce the central longitudinal cross-section of the setup. A hydraulic potential was applied on the boundary of the model corresponding to the upstream side of the setup and to the circular outlet.

Simulations of small-scale piping tests were performed using both a combination of two fine sand layers with an intermediate coarse sand layer and only one homogeneous equivalent layer of fine sand and coarse sand. The original and adjusted 2-forces Sellmeijer piping models were adopted (Sellmeijer et al., 2011). The adjusted model allows incorporating the effect of the relative density, uniformity and roundness. Figure 10 presents the numerically computed critical heads compared to the experimental results for heterogeneous experiments and homogeneous equivalents.

It appeared that in the numerical simulations of heterogeneous tests the computed critical head at which piping took place in the downstream fine sand layer was lower than the critical head of equivalent homogeneous tests with fine sand. This phenomenon was observed also in the experiments.

Experiments described in this paper and by Van Beek et al. (2008) showed that combination of fine and coarse sand resists the growth of piping channels stronger than each of the homogeneous sands alone. Simulation of experiments on Itterbeck 333 $\mu \mathrm{m}$ sand reproduced this phenomenon using both the original and adjusted 2-forces Sellmeijer piping model. It was noted that in the simulation of the experiments on Itterbeck $431 \mu \mathrm{m}$ sand only the adjusted piping model was able to reproduce this phenomenon. This discrepancy was explained considering that, as shown by Van der Zee (2011), for medium and coarse sand types the larger the coefficient of uniformity and the grain size are, the higher the critical head computed by the original piping is in comparison with the adjusted piping model.

It was found that in the numerical simulation of heterogeneous tests the critical head calculated by MSeep at which channel formation took place in the downstream fine layer was higher than the measured values. Van Beek et al. (2015) have shown that experiments having a 3D configuration result in considerably lower critical gradients than a 2D configuration. Because $3 \mathrm{D}$ groundwater flow conditions cannot be accurately simulated by a $2 \mathrm{D}$ numerical model, MSeep couldn't predict correctly the critical head of the tests.

In case of numerical simulations of tests with combination of fine and coarse sand, it was noted that the computed final critical head was underestimated by MSeep if compared to the corresponding experiments. It appeared that the better simulated tests were B-SZ-B-177 and B-M3D-B-179, which were the experiments where only one central pipe developed through the intermediate layer. The observed discrepancies could be explained by the fact that a three-dimensional erosion pattern cannot be correctly reproduced by MSeep and that the Sellmeijer model does not account for the primary erosion mechanism, which can explain, according to Van Beek et al. (2015), the increase of piping resistance resulting from the variation of grain size encountered in layered sand samples. 


\subsection{D numerical simulation}

MODFLOW is a three-dimensional finitedifference groundwater model where groundwater flow is simulated using a block-centered finitedifference approach (Harbaugh, 2005). MODFLOW was used to simulate the groundwater flow through the sand sample of test B-M3D-B-179 at different stages of pipe development in order to investigate the impact of the piping channels on the seepage pattern in case of macro-scale heterogeneity. Test BM3D-B-179 was chosen for the simulation because its erosion pattern could be easily reproduced in the numerical model and because during this experiment the pipe developed below the riser tubes installed at the top of the setup allowing the head in the pipe to be measured.

Test B-M3D-B-179 was simulated at different stages of pipe development: before any sand transport occurred $(\Delta \mathrm{H}$ at $0.05 \mathrm{~m})$, when the pipe developed up to the downstream fine-coarse sand interface and perpendicular to the direction of flow $(\Delta \mathrm{H}$ at $0.15 \mathrm{~m})$; when the pipe partially developed in the intermediate layer $(\Delta \mathrm{H}$ at $0.20 \mathrm{~m})$ and when the pipe developed up to the upstream coarse-fine sand interface $(\Delta \mathrm{H}$ at $0.30 \mathrm{~m})$. Pipe was modelled as a straight channel using the approach described by Van Beek et al. (2014). The depth of the pipe was chosen to be constant and, according to Van Beek et al. (2015), approximately equal to $2 \mathrm{~mm}$. Vertical pipe edges were used in the model. Pipe width was measured from the experiment and it was assumed between $0.5 \mathrm{~cm}$ and $1 \mathrm{~cm}$. The numerical simulation required a simplification of the pipe, which was modelled as a porous material with a higher permeability than the sandy aquifer. According to Bersan et al. (2013), the Hagen-Poiseuille flow in the pipe was described by the Darcy's law using a fictitious permeability:

$$
K^{*}=\frac{2 D_{h}^{2}}{\beta} \rho g \frac{1}{\mu}
$$

Where $\rho\left(\mathrm{kg} / \mathrm{m}^{3}\right)$ is the fluid density, $\mu(\mathrm{kg} /(\mathrm{m} \cdot \mathrm{s}))$ is the fluid viscosity, $g\left(\mathrm{~m} / \mathrm{s}^{2}\right)$ is the gravity acceleration, $D_{h}(m)$ is the hydraulic diameter and $\beta$ is a friction factor that, in case of rectangular pipe crosssection geometry, is calculated using the equation provided by Papautsky et al. (1999) and it is a function of the depth and width of the pipe. $\mathrm{K}^{*}$ was estimated equal to $2.270 \mathrm{~m} / \mathrm{s}$ for the central pipe parallel to flow direction, and equal to $2.020 \mathrm{~m} / \mathrm{s}$ for the transverse erosion channel perpendicular to the direction of flow and adjacent to the downstream finecoarse sand interface. For fine sand layers, permeability was assumed equal to the one measured in the experiment. For coarse sand layers, permeability was estimated using the formula of Den Adel (1987). An additional thin vertical layer with low
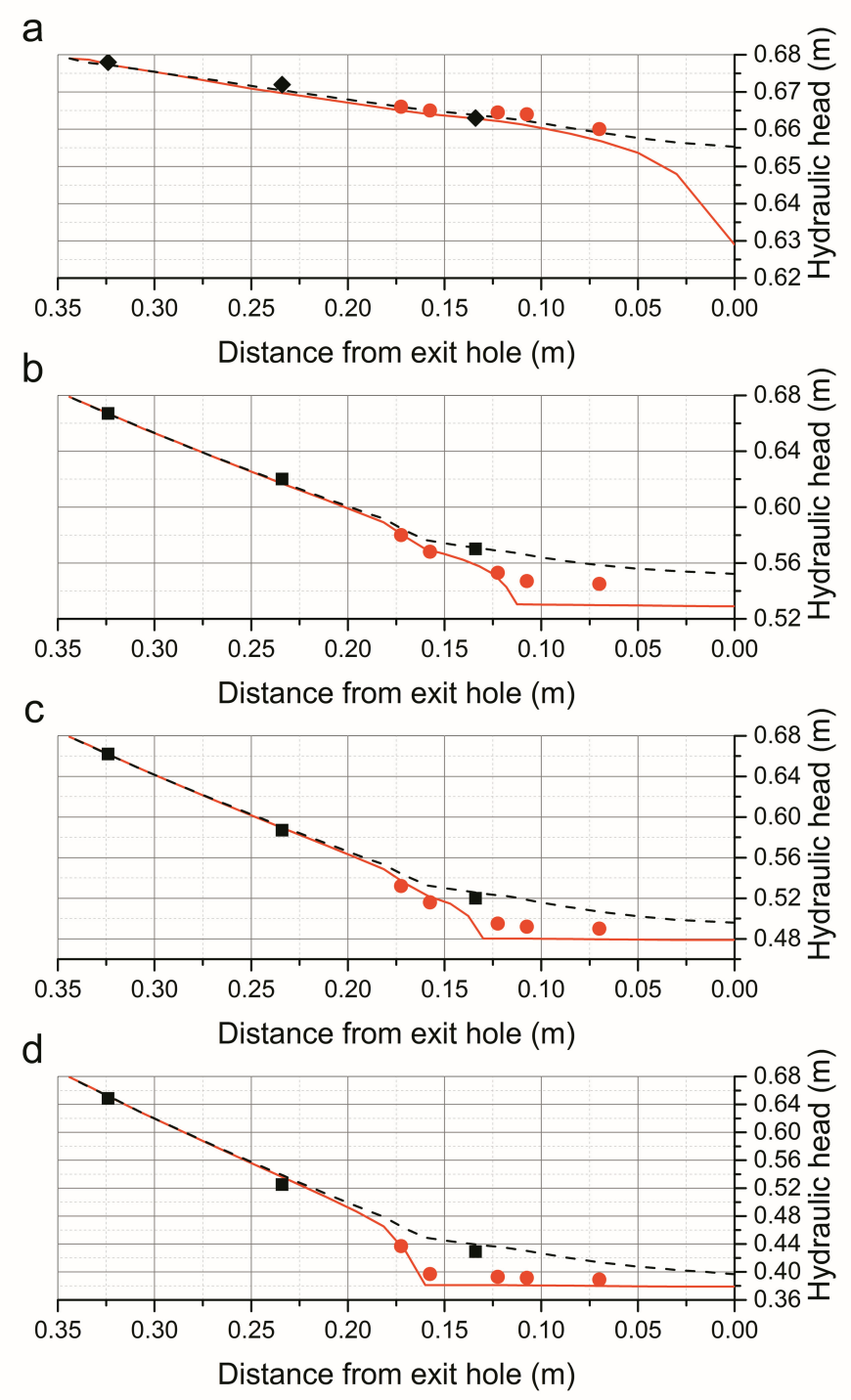

$\begin{array}{lr}\text { Upper simulated head } & --- \text { Bottom simulated head } \\ \text { Upper measured head } & \text { Bottom measured head }\end{array}$

Figure 11. Experimental measurements and numerical results of the head along the middle axis for an overall head drop of $0.05 \mathrm{~m} \mathrm{(a)}, 0.15 \mathrm{~m}$ (b), $0.20 \mathrm{~m}$ (c) and $0.30 \mathrm{~m}$ (d) for test BM3D-B-179.

permeability $(2.5 \mathrm{E}-05 \mathrm{~m} / \mathrm{s})$ was inserted upstream the intermediate layer in order to take into account the effect of mixing of fine and coarse sand grains. The sand sample was spatially discretized by a three-dimensional grid of cells, each one containing a node at which the head was computed. The head drop across the sand sample was simulated by attributing a constant head to the cells corresponding to the upstream side of the experimental setup and to the area around the downstream circular outlet, which resembled the fluidized sand volume around the exit hole and whose area varied from $12 \mathrm{~cm}^{2}$ to $44.8 \mathrm{~cm}^{2}$.

The groundwater model of experiment B-M3DB-179 was tested by comparing the head computed in the pipe and in the sand sample to the experimental values measured by the riser tubes at the top and at the bottom of the sample. Figure 11 presents the distribution of the potential simulated along the 


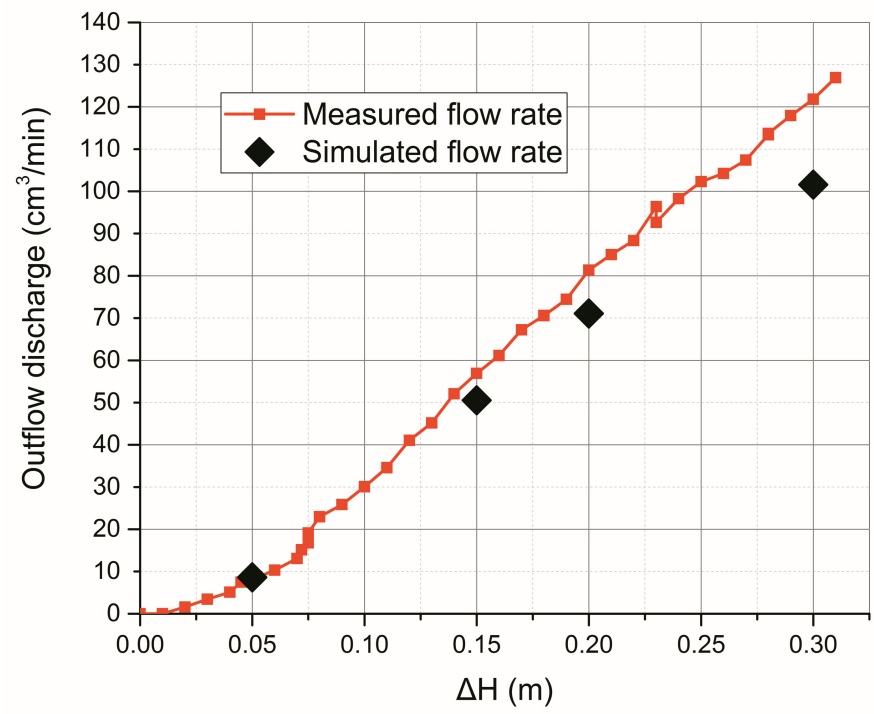

Figure 12. Comparison between measured and simulated outflow discharge for test B-M3D-B-179.

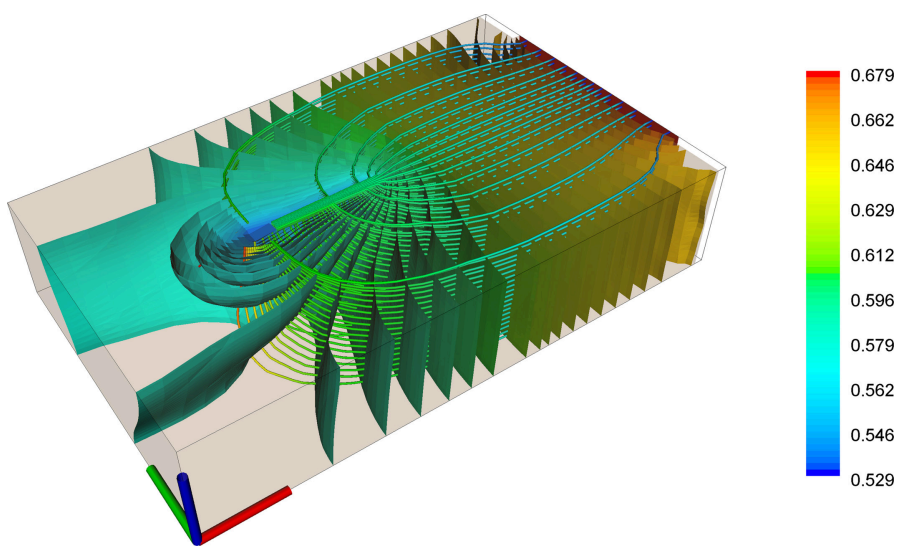

Figure 14. Simulated seepage pattern through the sample of test B-M3D-B-179 for length of the transverse erosion channel equal to $1 \mathrm{~cm}$.

middle axis for each modelled pipe configuration. An acceptable match was achieved between experimental measurements and simulation output for different pipe lengths but the numerical model underestimated the head in the piping channel. Figure 12 shows the outflow discharge computed by the numerical simulation compared to the experimental measured flow rate. It was found that the numerical model resulted in a slightly underestimation of the flow rate.

MODFLOW was used to investigate the impact of piping on the seepage pattern through a sandy aquifer with macro-scale heterogeneity. The groundwater model of experiment B-M3D-B-179 with head drop of $0.15 \mathrm{~m}$ and pipe straight length of 11.5 $\mathrm{cm}$ was considered. Numerical simulations with geometric symmetry were performed varying the total length of the transverse erosion channel from $1 \mathrm{~cm}$ (corresponding to the situation in which only the central pipe parallel to the flow direction developed up to the coarse sand) to $30 \mathrm{~cm}$ (corresponding to the situation in which the pipe developed adjacent to the interface toward the lateral sides of the sample).

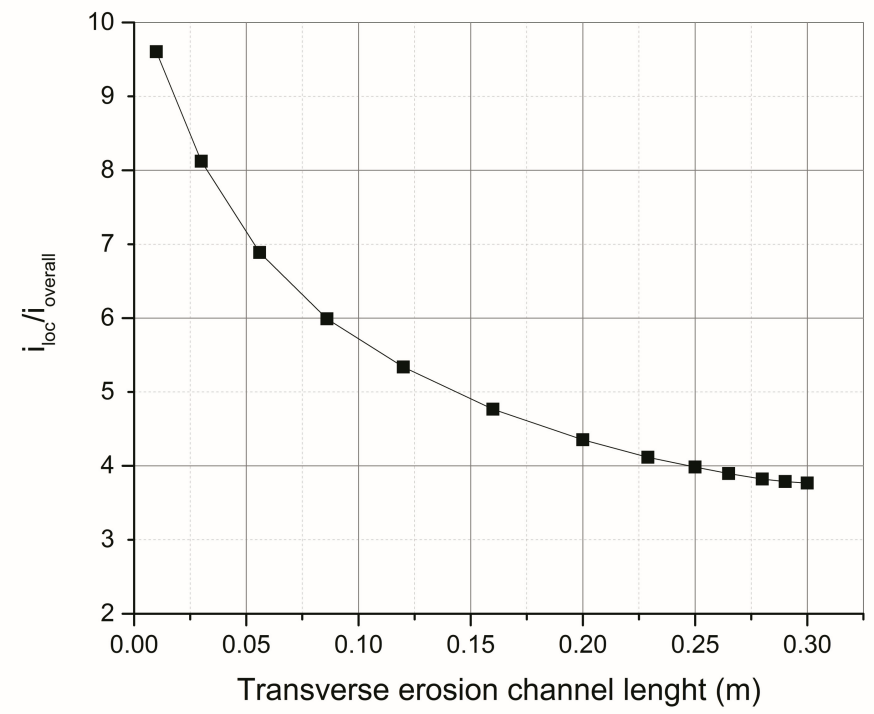

Figure 13. Simulated local gradient at the tip of the pipe of test B-M3D-B-179 $(\Delta \mathrm{H}=0.15 \mathrm{~m})$.

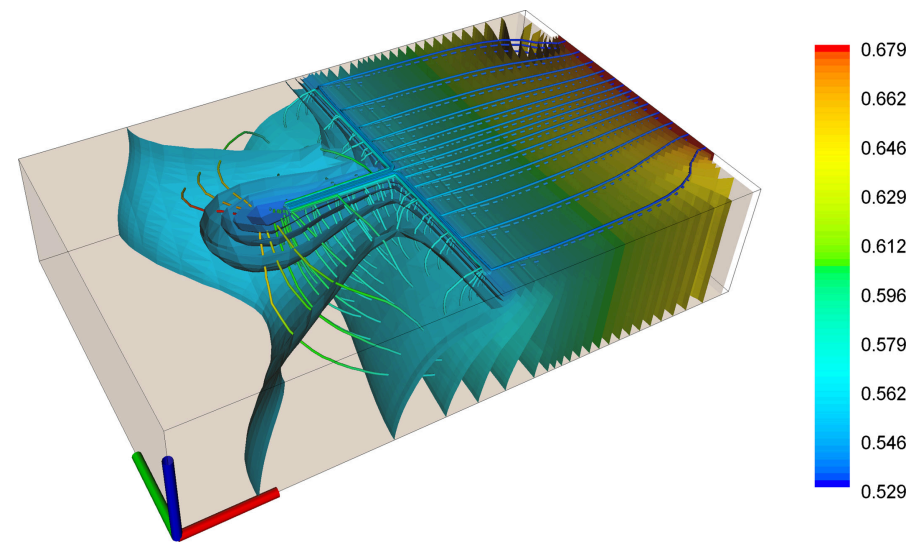

Figure 15. Simulated seepage pattern through the sample of test B-M3D-B-179 for length of the transverse erosion channel equal to $30 \mathrm{~cm}$.

In each simulation the local gradient at the tip of the central pipe was determined, according to Van Beek et al. (2015), computing the head in the pipe close to the tip and the head in the sand upstream of the pipe at a distance from the tip equal to 30 times the mean grain diameter of the sand, which is equal to $0.849 \mathrm{~cm}$ for Itterbeck $333 \mu \mathrm{m}$ sand. Figure 13 shows the local gradient at the pipe tip normalized with respect to the overall gradient as a function of length of the transverse erosion channel. Although it was noted that simulations underestimated the head in the piping channel, resulting likely in overestimation of the local gradient, it was found, for the considered groundwater model, that length increase of the transverse erosion channel could result in a maximum reduction in local gradient of $61 \%$. Figures 14 and 15 show the rendering of the $3 \mathrm{D}$ groundwater flow pattern through the sand sample simulated by the numerical model for length of the transverse erosion channel equal respectively to $1 \mathrm{~cm}$ and $30 \mathrm{~cm}$. In the first case only the central pipe parallel to the flow direction is present. Figure 14 shows that the influence of the piping channel on the seepage pat- 
tern is such that there is a dense concentration of flow lines converging at the tip of the central pipe with water entering both at the head and at the bottom of the pipe. In the second case the transverse erosion channel is completely developed up to the lateral sides of the sand sample. Figure 15 shows that the flow is distributed uniformly along the downstream interface of the intermediate layer because water flows from the porous matrix into the transverse erosion channel along its whole length. Therefore, this could explain why, for the same overall gradient, increase of transverse erosion channel length, which was caused by the presence of macro-scale heterogeneity in the sand sample, resulted in decrease of the local gradient at the tip of the central pipe. Because of this phenomenon, macro-scale heterogeneity was expected to result in a larger increase of piping resistance of the sand sample than the one explained only by reference to the variation in grain size. The reason was that if the increase of the length of the transverse erosion channel leads to reduction of the local gradient at the tip of the pipe, then a higher overall gradient will be required in order that the local gradient may be high enough to exceed the critical value described by Van Beek et al. (2015) for pipe progression due to primary erosion.

\section{CONCLUSIONS}

Small-scale piping experiments on heterogeneous sand samples revealed that variation of sand properties in the path of the pipe caused by micro-scale and macro-scale heterogeneity has a significant influence on the progression of pipe development increasing the piping resistance of the sandy aquifer. In all the micro-scale heterogeneity experiments it was found that layered sand samples were less prone to piping as they resulted in a critical head higher than homogeneous equivalents. In each macro-scale heterogeneity experiment the progression of the pipe was interrupted at the interface between fine and coarse sand and, until a significant head increase didn't occur, the pipe developed adjacent to the interface. It was found that, in case of heterogeneous experiments, the critical head was higher compared to equivalent experiments on homogeneous fine sand.

Numerical simulations of the piping experiments were performed in case of macro-scale heterogeneity. Erosion results of the 2D groundwater model extended with a piping module didn't fit the experimentally obtained critical heads. The observed discrepancies could be explained by the fact that the 2D numerical simulations cannot predict the 3D flow configuration occurred in the piping experiments and that the Sellmeijer model does not account for the primary erosion mechanism. The 3D groundwater model correctly simulated the 3D seep- age pattern through a heterogeneous sand sample affected by piping, although the head in the pipe and the outflow discharge were slightly underestimated. Simulations demonstrated that, for the same overall gradient, development of an erosion channel perpendicular to the flow direction led to decrease of the local gradient at the tip of the pipe. Therefore, increase in piping resistance observed in macro-scale heterogeneity experiments could be explained not only by reference to variation in grain size but also taking into account the influence on the seepage pattern of the transverse erosion channel developed perpendicular to the coarse sand layer.

Further experimental and numerical research is required to allow for 3D modelling of backward erosion piping in heterogeneous sands in order to include in the safety assessment of water-retaining structures the effect of natural variation in soil properties on piping and to develop innovative piping prevention measures.

\section{ACKNOWLEDGEMENTS}

The present research has been carried out at Deltares within the Erasmus+ Traineeship Programme funded by the European Union. The authors gratefully acknowledge F.M. Schenkeveld for his help and expertise during the design and execution of the tests.

\section{REFERENCES}

Aureli, F. \& Mignosa, P. 2004. Flooding Scenarios Due to Levee Breaking in the Po River. Water Management 157(1): 3-12.

Bersan, S., Jommi, C., Koelewijn, A.R., Simonini, P. 2013. Applicability of the fracture flow interface to the analysis of piping in granular material. In Proceedings of COMSOL Conference.

Calabresi, G., Colleselli, F., Danese, D., Giani, G., Mancuso, C., Montrasio, L., Nocilla, A., Pagano, L., Reali, E., Sciotti, A. 2013. Research study of the hydraulic behaviour of the Po River embankments. Canadian Geotechnical Journal 50(9): 947-960.

Camici, S., Barbetta, S., Moramarco, T. 2015. Levee body vulnerability to seepage: The case study of the levee failure along the Foenna stream on 1 January 2006 (central Italy). Journal of Flood Risk Management.

CUR 2010. CUR 233: Interface stability of granular filter structures. Gouda.

De Lange, D.A., Van Beek, V.M., Schenkeveld, F.M., Van der Linden, T.I., Negrinelli, G. 2016. Preparation techniques for unconventional sand samples. In Proceedings of the $3 \mathrm{rd}$ European Conference on Physical Modelling in Geotechnics.

Deltares, 2016. MSeep user manual, version 15.1, January 2016. Delft: Deltares.

Den Adel, H. 1987. Re-analysis of permeability measurements using Forchheimer's equation. In Report C0-272550/56. Delft: Delft Geotechnics.

Harbaugh, A.W. 2005. The U.S. Geological Survey Modular Ground-Water Model - the Ground-Water Flow Process. In U.S. Geological Survey Techniques and Methods 6-A16. 
Koelewijn, A.R., De Vries, G., Van Lottum, H., Förster, U., Van Beek, V.M., Bezuijen, A. 2014. Full-scale testing of piping prevention measures: three tests at the Ijkdijk. In Proceedings of the 8th International Conference on Physical Modelling in Geotechnics: 891-897.

Mazzoleni, M., Bacchi, B., Barontini, S., Di Baldassarre, G., Pilotti, M., Ranzi, R. 2014. Flooding hazard mapping in floodplain areas affected by piping breaches in the Po River, Italy. Journal of Hydrologic Engineering 19(4): 717 731.

Papautsky, I., Gale, B.K., Mohanty, S., Ameel, T.A., Frazier, A.B. 1999. Effects of rectangular microchannel aspect ratio on laminar friction constant. In Proceedings of the SPIE Microfluidic Devices and Systems: 147-158.

Ranzi, R., Bacchi, B., Barontini, S., Ferri, M., Mazzoleni, M. 2013. Levee breaches statistics, geotechnical uncertainty, residual risk in flood hazard mapping. In Proceedings of 35th IAHR World Congress.

Sellmeijer, J. B. 2006. Numerical computation of seepage erosion below dams (piping). In Proceedings of the 3rd International Conference on Scour and Erosion: 596-601.

Sellmeijer, J.B., Lopéz De La Cruz, J., Van Beek, V.M., Knoeff, J.G. 2011. Fine-tuning of the backward erosion piping model through small-scale, medium-scale and IJkdijk experiments. European Journal of Environmental and Civil Engineering 15(8): 1139-1154.

Van Beek, V.M., Koelewijn, A.R., Kruse, G., Sellmeijer, J.B., Barends, F. 2008. Piping phenomena in heterogeneous sands - experiments and simulations. In Proceedings of the 4th International Conference on Scour and Erosion: 453459.

Van Beek, V.M., Vandenboer, K., Bezuijen, A. 2014. Influence of sand type on pipe development in small- and mediumscale experiments. In Proceedings of the 7th International Conference on Scour and Erosion: 111-120.

Van Beek, V.M., Van Essen, H., Vandenboer, K., Bezuijen, A. 2015. Developments in modelling of backward erosion piping. Géotechnique 65(9): 740-754.

Van der Zee, R.A. 2011. Influences of sand characteristics on the piping process. Master's Thesis, Delft University of Technology.

Vrijling, J.K. 2010. Piping: Realiteit of Rekenfout?. Rijkswaterstaat, Waterdienst. 